\title{
Super-Clausius-Clapeyron Scaling of Extreme Hourly Convective Precipitation and Its Relation to Large-Scale Atmospheric Conditions ${ }^{\mathscr{O}}$
}

\author{
G. LENDERINK \\ Royal Netherlands Meteorological Institute, De Bilt, Netherlands \\ R. BARBERO \\ School of Civil Engineering and Geosciences, Newcastle University, Newcastle-upon-Tyne, United Kingdom \\ J. M. LORIAUX \\ Royal Netherlands Meteorological Institute, De Bilt, and Environmental Science Department, \\ Radboud University, Nijmegen, Netherlands \\ H. J. FOWLER \\ School of Civil Engineering and Geosciences, Newcastle University, Newcastle-upon-Tyne, United Kingdom
}

(Manuscript received 15 November 2016, in final form 14 March 2017)

\begin{abstract}
Present-day precipitation-temperature scaling relations indicate that hourly precipitation extremes may have a response to warming exceeding the Clausius-Clapeyron (CC) relation; for the Netherlands the dependency on surface dewpoint temperature follows 2 times the $\mathrm{CC}$ relation (2CC). The authors' hypothesisas supported by a simple physical argument presented here-is that this $2 \mathrm{CC}$ behavior arises from the physics of convective clouds. To further investigate this, the large-scale atmospheric conditions accompanying summertime afternoon precipitation events are analyzed using surface observations combined with a regional reanalysis. Events are precipitation measurements clustered in time and space. The hourly peak intensities of these events again reveal a $2 \mathrm{CC}$ scaling with the surface dewpoint temperature. The temperature excess of moist updrafts initialized at the surface and the maximum cloud depth are clear functions of surface dewpoint, confirming the key role of surface humidity on convective activity. Almost no differences in relative humidity and the dry temperature lapse rate were found across the dewpoint temperature range, supporting the theory that 2CC scaling is mainly due to the response of convection to increases in near-surface humidity, while other atmospheric conditions remain similar. Additionally, hourly precipitation extremes are on average accompanied by substantial large-scale upward motions and therefore large-scale moisture convergence, which appears to accelerate with surface dewpoint. Consequently, most hourly extremes occur in precipitation events with considerable spatial extent. Importantly, this event size appears to increase rapidly at the highest dewpoint temperature range, suggesting potentially strong impacts of climatic warming.
\end{abstract}

\section{Introduction}

A number of extreme precipitation events struck Europe in spring and early summer 2016, causing extensive flooding in France and Germany and more localized flooding in the Netherlands. These extreme events have

Supplemental information related to this paper is available at the Journals Online website: http://dx.doi.org/10.1175/JCLI-D-16-0808.s1.

Corresponding author: G. Lenderink, geert.lenderink@knmi.nl been partly attributed to global warming based on an analysis of the observed trends, combined with model simulations from regional and global climate models (van Oldenborgh et al. 2016). Increases in precipitation extremes with global warming are primarily understood from simple thermodynamics-an increase in moisture content of the atmosphere-while contributions from changes in atmospheric dynamics and microphysics are still rather uncertain (Westra et al. 2014; Singh and O'Gorman 2014; O'Gorman 2015; Lenderink and Attema 2015; Fischer and Knutti 2016). 
These summertime precipitation extremes are often caused by convective showers, which could occur in isolation but are also often embedded within large-scale cyclonic circulation types (van Oldenborgh et al. 2016; Hand et al. 2004). The scale of these showers varies from several tens to a few hundred kilometers when they are clustered in mesoscale convective systems (Houze 2004). Current climate models do not resolve convective clouds and therefore rely on statistical prescriptions, called parameterizations, to simulate their average effects across a model grid cell. It therefore remains to be seen whether these climate model projections produce sufficiently reliable simulations of convective showers. Convection-permitting models (e.g., Prein et al. 2015) run at a much higher resolution and studies sometimes show a much stronger precipitation response to warming than for models in which convection is parameterized (e.g., Kendon et al. 2014; Meredith et al. 2015). However, in other studies reasonably similar results have been obtained (Ban et al. 2015).

Observation-based relationships between hourly precipitation and temperature or humidity could provide additional information on the sensitivity of subdaily precipitation extremes to global warming. Scaling relations of hourly precipitation intensity on temperature have revealed a dependency greater than the increase in saturation specific humidity (e.g., Lenderink and van Meijgaard 2008; Westra et al. 2014). The increase in saturation specific humidity is governed by the ClausiusClapeyron (CC) relation, yielding an increase of approximately $6 \%$ to $7 \%$ per warming degree. For some time the CC relation has been used to provide a baseline estimate of the influence of global warming on the intensity of precipitation extremes (Pall et al. 2007; Allen and Ingram 2002).

Various scaling relations of hourly precipitation extremes on temperature have been obtained worldwide (Westra et al. 2014; Hardwick Jones et al. 2010; Panthou et al. 2014; Drobinski et al. 2017; Mishra et al. 2012). Often a scaling exceeding the CC relation, a so-called super-CC scaling, is observed for an intermediate temperature range, while intensities do not increase further or may even fall off, with the highest temperatures showing a hook shape (Westra et al. 2014). However, temperature is not necessarily a good predictor of atmospheric humidity, since a $1{ }^{\circ} \mathrm{C}$ temperature rise corresponds to a $6 \%-7 \%$ increase in moisture only under the assumption of a constant relative humidity (Lenderink and Attema 2015). Even for the relatively humid climate of the Netherlands this assumption is not always met for the highest temperatures (Lenderink and van Meijgaard 2010). This simple drying effect could explain the decreasing precipitation intensities for the highest temperature regime, or even the negative scaling for the full temperature range in the drier climate regimes, for example as seen in parts of the Mediterranean Sea (Drobinski et al. 2017) and northern Australia (Hardwick Jones et al. 2010).

By using the dewpoint temperature-the temperature defined by cooling air adiabatically until saturation occurs-assumptions about relative humidity are avoided, and a $1^{\circ} \mathrm{C}$ dewpoint temperature rise is by definition equal to a $6 \%-7 \%$ moisture increase. Using dewpoint temperature measured a few hours before each precipitation observation, we obtained a consistent 2 times CC (2CC) scaling (12\%-14\% per degree) of hourly precipitation extremes for data in the Netherlands and Hong Kong (Lenderink et al. 2011). For 10-min precipitation intensities such a $2 \mathrm{CC}$ scaling was even obtained over an almost $20^{\circ} \mathrm{C}$ dewpoint temperature range (Loriaux et al. 2013).

This seemingly regular behavior of extreme intensities over such a large dewpoint temperature range for data from the Netherlands suggests that there is an underlying physical mechanism. In literature, it has been suggested that latent heat release could provide a positive feedback leading to super-CC scaling behavior (e.g., Trenberth et al. 2003).

To explain how latent heat released during cloud condensation could be responsible for the 2CC relation we propose the following simple physical reasoning. We consider rising air that moves upward with typical velocity $w$ and absolute humidity $q$ at cloud base. If we assume that the moisture flux at the cloud base is the dominant moisture source of the cloud, then the precipitation intensity $P$ will be proportional to this moisture flux, that is $P \sim w q$. Latent heating in the cloud will also be proportional to $P$. If we now assume that the kinetic energy of the rising air $\left(\sim 1 / 2 w^{2}\right)$ increases proportionally with the latent heating, then $w^{2} \sim P$. This may hold if we assume that there is a fixed efficiency of the conversion of latent heat to kinetic energy by buoyancy forces and that the dissipation of kinetic energy is proportional to the kinetic energy itself (see the online supplemental material). From these two relations, it follows simply that $P \sim q^{2}$. In other words, the precipitation intensity increases quadratically with the absolute humidity: a $2 \mathrm{CC}$ relation. Although this explanation is very simplistic, and ignores the complex three-dimensional dynamics of turbulence in convective clouds, there is some modeling support for our theory. Results from a sensitivity experiment in a mesoscale model for an idealized squall line showed that the moisture flux at cloud base scales roughly as $2 \mathrm{CC}$, and the updraft velocity as CC (Singleton and Toumi 2013). In a simple updraft model of the cloud core we also found that the lateral moisture flux into the column, and 
related precipitation, followed $2 \mathrm{CC}$ behavior, but the vertical moisture flux at cloud base (which in this model is not affected by latent heat release) followed only CC scaling (Loriaux et al. 2013).

Changes in atmospheric stability with climate change could play a crucial role in this context (Frierson 2006). The modeling results cited above have been obtained with uniform vertical warming profiles. However, adjusting the profiles according to a moist adiabat with greater warming in the upper troposphere leads to weaker dependencies as, in that case, the buoyancy of an updraft will not increase with warming (Loriaux et al. 2013). This may also explain the lower sensitivities, mostly close to the CC relation, in convective resolving/ permitting simulations of tropical precipitation using radiative-convective equilibrium experiments (Romps 2011; Muller et al. 2011).

It has also been proposed that $2 \mathrm{CC}$ scaling is caused by statistical effects unrelated to the physics (Haerter and Berg 2009). The main argument is that large-scale atmospheric conditions could vary systematically between cooler and warmer surface conditions, leading to different frequencies of occurrence of large-scale and convective precipitation events. So, for example, if the cold temperature regime is dominated by less intense large-scale rain related to frontal systems, whereas the warmer temperatures are dominated by more intense convective precipitation, a transition temperature regime exists with a rapid increase in precipitation intensity. If this is indeed the case, then super-CC scaling may not be good indicator of potential increases in precipitation intensities with climate change.

Several studies have attempted to separate out convective and large-scale precipitation events with varying outcomes. Whereas some studies found that increases in both large-scale and convective extremes satisfied the $\mathrm{CC}$ rate, other analyses reported on a clear super-CC scaling (Berg et al. 2013; Berg and Haerter 2013; Molnar et al. 2015). However, it is very difficult to come up with a clear distinction between large-scale and convective events as precipitation events may have both a large-scale and a convective component, such as convective precipitation near cold fronts. Another complication is that the definition of convective precipitation is often directly or indirectly linked to the intensity itself. For instance, Molnar et al. (2015) and Ivancic and Shaw (2016) used lightning as an indicator of convective precipitation. While lightning is indeed an indicator of convective precipitation, the absence of lightning does not necessarily imply that the event is not convective, and, if this effect is systematic across (dewpoint) temperature, one would introduce a statistical effect.

Framing this point more generally, we argue that the above statistical mixing of precipitation types occurs if there is a systematic variation of the large(r)-scale atmospheric conditions with dewpoint temperature. We argue that the scaling provides valuable information on climate change if atmospheric conditions remain similar across the different dewpoint temperature bins with the exception of the higher temperature and humidity. In this case, the scaling would primarily reflect changes in hourly precipitation extremes due to a warmer and more humid atmosphere. By contrast, if atmospheric conditions systematically change across dewpoint temperature bins, then the scaling may primarily reflect the consequence of differences in the large-scale atmospheric forcing conditions.

However, it is not trivial to quantify similar large-scale atmospheric conditions. This depends on which measures of the atmospheric state are relevant, what is considered large-scale, and also on how we define similar. We do not claim to have definite answers to these questions as they require precise knowledge on the conditions leading to extreme precipitation. Although there are a considerable number of publications on conditions potentially leading to extreme precipitation, sometimes called ingredients, there is no one-to-one correspondence between these conditions and extreme precipitation (Doswell et al. 1996; Loriaux et al. 2016; Davies et al. 2013; Lepore et al. 2016). In this paper we use the following measures of the (large-scale) atmospheric state: 1) the large-scale vertical velocity, which provides a mechanism of triggering convection and large-scale moisture convergence; 2) the atmospheric stability both in terms of dry as well as moist processes, which provides information on the potential strength of convection and the influence of moist processes herein; and 3) relative humidity, which influences the cloudbase height, the dilution of a moist updraft and consequently the cloud-top height, and the evaporation of rain and formation of downdrafts. We investigate how these measures vary with the dewpoint temperature. We then contrast these differences with those occurring for different precipitation intensities.

The paper is organized as follows. First, we will associate large-scaling atmospheric condition to precipitation events employing the methods in Loriaux et al. (2016) (section 2), followed by analyzing the scaling behavior of peak intensities of precipitation events (section 3). Finally, we will investigate large-scale atmospheric conditions within the framework of the scaling diagram (section 4).

\section{Data and methods}

Following Loriaux et al. (2016), we use a combination of surface observations and model outputs from a high-resolution dynamical downscaling of ERA-Interim 


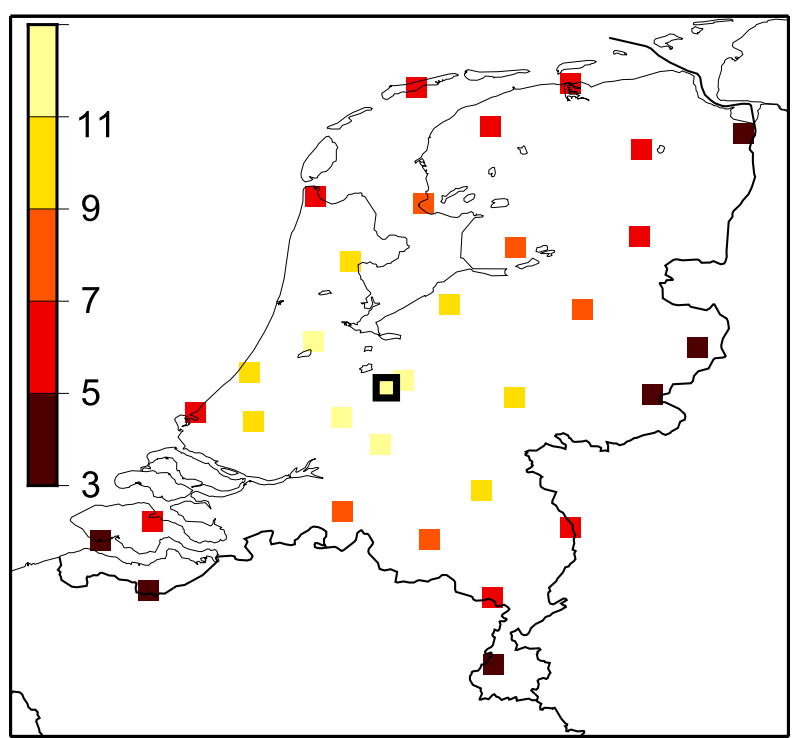

FIG. 1. Location of the automatic weather stations (AWS) in the Netherlands. Shown in color is the number of neighboring stations within a distance of $70 \mathrm{~km}$.

(Dee et al. 2011) and perform a precipitation event-based analysis. Surface observations are given by hourly observations of temperature, humidity, and rainfall at approximately 30 automatic weather stations (AWS) spread rather evenly over the Netherlands (see Fig. 1). The number of stations varies slightly with time (between 28 and 32 stations).

\section{a. Classification of events}

We use a simple classification of hourly precipitation measurements at 30 stations in the Netherlands into events (Loriaux et al. 2016). An event-based analysis is used to avoid double counting of the same atmospheric state and to ensure the independence of the data. Also, taking all station data into account would lead to strong convective atmospheric conditions being classified as belonging to a weak precipitating class as, even under these strongly convective conditions, only light or moderate rain is observed at most stations.

Events are defined by precipitation measurements at the AWS that are connected in time and space. This follows a two-step procedure. First, for each station, we assign hourly precipitation observations to the same event if they are continuous in time, or have at most one dry hour in between. Each event is assigned a unique event number. Second, we combine the events when they overlap in time and in space within a distance of $70 \mathrm{~km}$. We have chosen this distance in order to have a reasonable number of stations that are classified as nearby: at least 3 to 5 for stations near the borders of the Netherlands, but mostly between 6 and
13 for stations located in the interior of the Netherlands (see Fig. 1).

To discriminate between atmospheric conditions representative of rainfall events and the conditions under which no rain occurred, we also defined dry events. This was performed by choosing days without rain at all stations, and by sampling randomly from a station and a time in the afternoon.

\section{b. Characterization of the atmosphere}

Model outputs consist of a downscaling of ERAinterim with the regional climate model RACMO2 (van Meijgaard et al. 2012) at 12-km resolution. RACMO2 was run in hindcast mode; that is, at 1200 UTC each day a 36-h forecast is started from ERA-Interim initial conditions and using ERA-Interim boundaries. The surface conditions are cycled through the integration. There is no additional assimilation of observations. The first $12 \mathrm{~h}$ of the forecast are neglected, and the time series from 12 to $36 \mathrm{~h}$ form a continuous time series. Model output from the grid points collocated with each AWS location is available at an hourly resolution and for all vertical model levels. The time period studied covers almost 20 years, from 1 January 1995 until June 2014, which was the end date of the RACMO2 simulations.

In this paper we compare the atmospheric conditions averaged across $20-50$ precipitation events, which are selected in the next section based on surface dewpoint temperature and peak intensity of the event. For such an average the modeled temperature and humidity profile for the grid point closest to De Bilt are generally close to the radiosonde launched at 1200 UTC at De Bilt. The temperature profile is almost identical with a typical error of $0.3^{\circ} \mathrm{C}$ (see the online supplemental material). Differences in relative humidity are larger. As an example, we show in Fig. 2 the mean relative humidity profile at 1200 UTC for different selections of events, ranging from the summertime mean (left) to dry, wet, and extreme events occurring with moderate (middle) and very high surface humidity (right). The model reproduces the differences in relative humidity between these different selections of events quite well up to 6-km height. Above $6 \mathrm{~km}$ the relative humidity in the model is (too) high compared to the radiosonde (see also the supplemental material).

We also consider the properties of an undiluted parcel rising from the surface, as used in the computation of the convective available potential energy (CAPE). Here the surface parcel is initialized by surface observations of temperature and humidity, and this leads to CAPE values that are very close to those derived from the radiosonde directly (Loriaux et al. 2016).

The model results do not reproduce the exact timing and location of the precipitation events, which is also not 

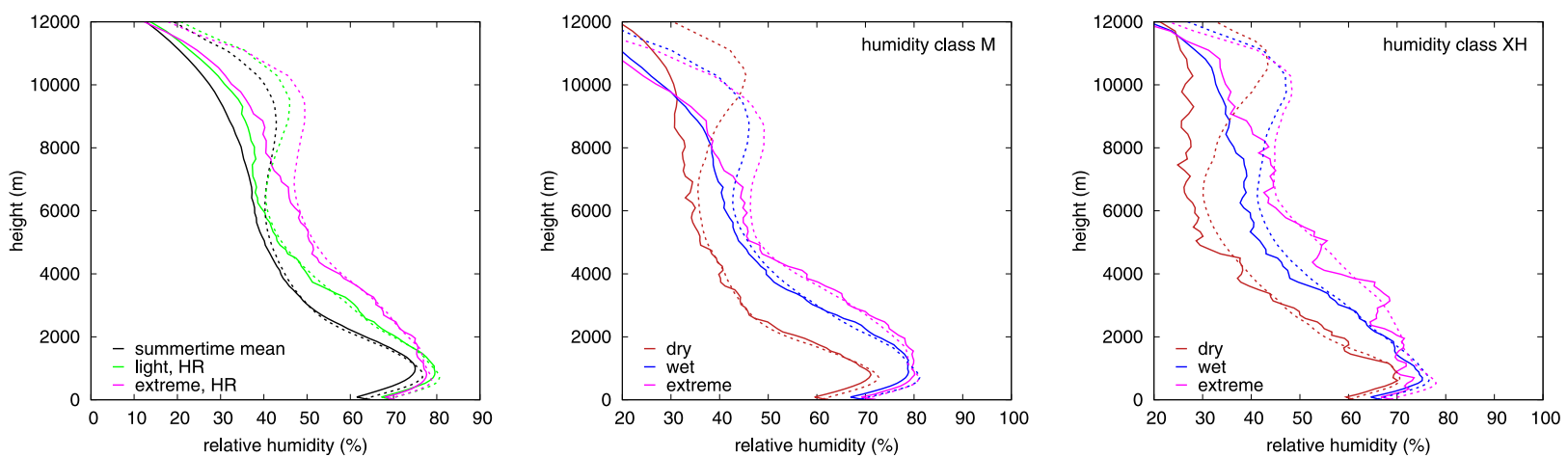

FIG. 2. Vertical profiles of relative humidity (compared to the water phase) at 1200 UTC averaged for a selection of precipitation events based on surface humidity and event peak precipitation (see Table 1 and section 3 for details on these humidity and intensity classifications): (left) mean summertime (black) and light and extreme precipitation events from HR humidity range and (middle),(right) dry, wet (all events with rain), and extreme precipitation for humidity classifications M and XH. Solid lines indicate radiosonde profiles, while dashed lines are model simulations.

expected given the highly nonlinear behavior of convective processes and the fact that the model does not explicitly resolve convection. However, the model reproduces the mean rainfall amounts for all selection of events, averaged across all stations and summed over the day, indicating that the large-scale moisture budget is realistically captured by the model (see the supplemental material).

For profiles of temperature, relative humidity, and horizontal wind we used hourly model output at the grid point collocated with the observation station where the peak of the precipitation is observed. For vertical velocity we aim to have a large-scale field representing conditions over a $100-200-\mathrm{km}$ scale, which is forced from the large-scale circulation. The vertical velocity therefore does not represent the vertical updraft motions in convective clouds. Hourly omega fields are only available at a few atmospheric levels. Therefore, we make use of the average omega profiles at grid points collocated with the AWS, but we note that comparison of these averages with the true spatially averaged fields leads to very similar outcomes (Loriaux et al. 2016).

\section{Analysis of precipitation events}

\section{a. Size of the events and distribution of precipitation intensity}

The selection of events leads to a large data reduction compared to the pooled station data. There are about $5.5 \times 10^{6}$ hourly observations, of which approximately $9 \%$ have a precipitation sum exceeding the wet threshold of $0.1 \mathrm{~mm}$. Merging in time about $2 \times 10^{5}$ events at single stations are identified, and further merging in space leads to a reduction in the number of events to almost $2.4 \times 10^{4}$ rainfall events. We use events from the summer half-year from April to September only, noting that most extreme events occur during this period. For example, there are 116 events with peak intensities above $20 \mathrm{~mm} \mathrm{~h}^{-1}$ of which only two events occur outside the summer half-year.

Here, the spatial extent of a precipitation event is defined by the fraction of the stations in the Netherlands with precipitation resulting from the event, and we refer to this as the area fraction. The majority, more than $70 \%$, of the events are rather small scale with area fractions below 0.1 , that is with a maximum of three stations involved (Fig. 3a). Approximately $10 \%$ of the events cover (almost) all of the Netherlands with area fractions above 0.9 .

We find a remarkable increase in the area fraction for the most humid days (Fig. 3b). The percentage of events with an area fraction exceeding different thresholds ranging from 0.1 (magenta) to 0.6 (blue) increases with surface dewpoint. In particular, for a dewpoint above $16^{\circ} \mathrm{C}$ the increase in the number of large-scale events is considerable. For instance, the percentage of the events with an area fraction exceeding 0.4 (cyan line) increases from values between $10 \%$ and $14 \%$ at dewpoint temperatures below $16^{\circ} \mathrm{C}$ to $22 \%$ for a dewpoint of almost $20^{\circ} \mathrm{C}$. This increase is close to being statistically significant (gray shaded area showing the $95 \%$ confidence interval) and it is very consistently obtained for different thresholds. Also, using a different radius to cluster the precipitation measurements into events, ranging from 50 to $100 \mathrm{~km}$, leads to qualitatively similar results (dashed lines in Fig. 3b).

To discriminate between large-scale and small-scale precipitation events we use an arbitrary area fraction of $30 \%$, equivalent to rain observed at approximately 10 stations. A too high threshold to discriminate between large-scale and small-scale events leads to a very limited number of large-scale events, whereas a low threshold 

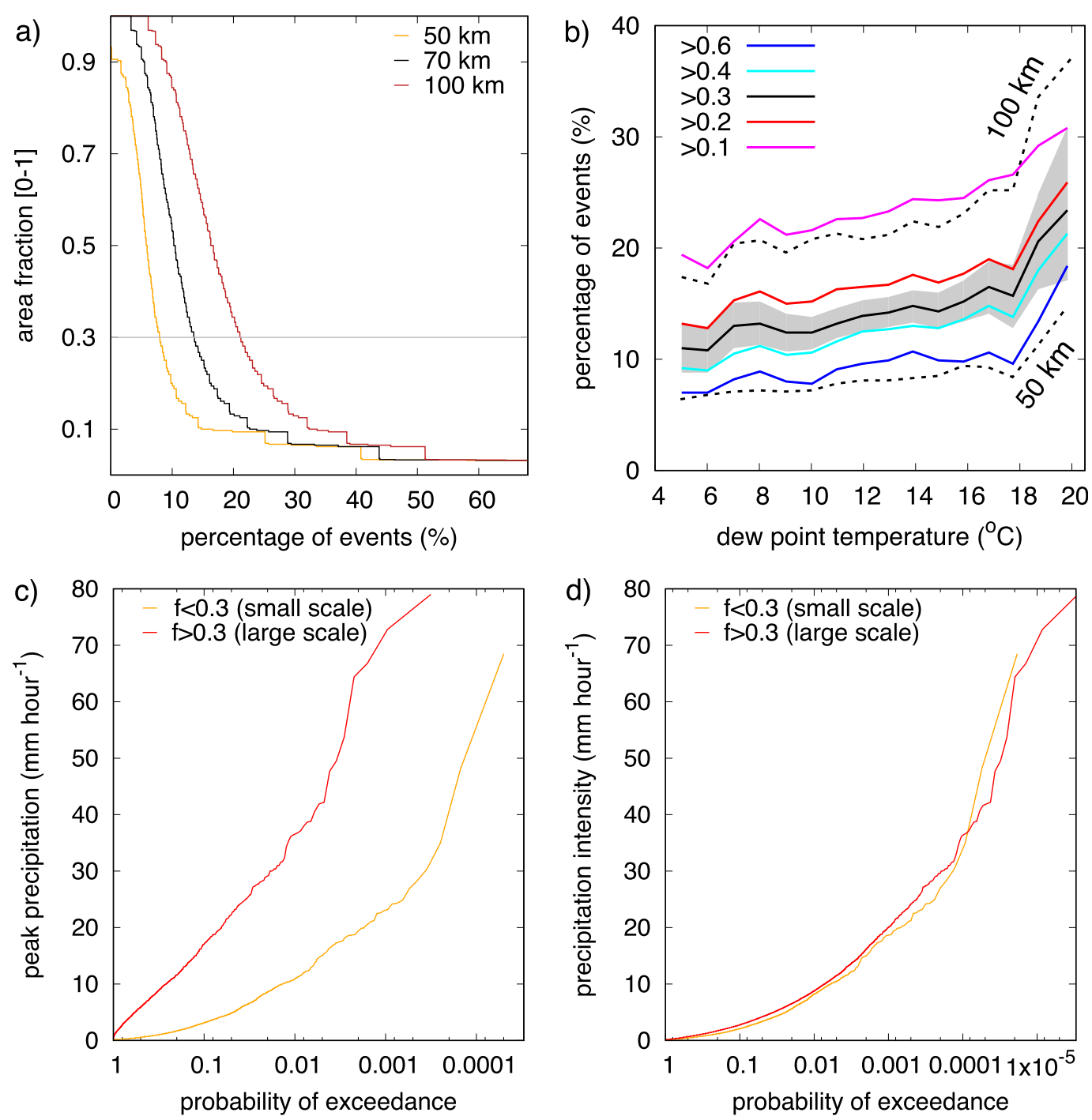

FIG. 3. (a) Distribution of event area fraction for the summer half-year for different values of the radius used to classify the measurements into events: $50 \mathrm{~km}$ (orange), $70 \mathrm{~km}$ (black; reference), and $100 \mathrm{~km}$ (brown). (b) Percentage of the number of events exceeding different area fractions (colors) as a function of dewpoint temperature (black dashed lines show results using 50- and 100-km radius, only for 0.3 area fraction). (c) Distribution of hourly peak intensities for large-scale (area fraction above 0.3) and small-scale events. (d) As in (c), but now for all hourly observations belonging to an event.

leads to a rather large sensitivity of the number of largescale events to this threshold. From a physical point of view, a large mesoscale convective system with a typical scale of $50-100 \mathrm{~km}$ (Houze 2004) moving from southwest to northeast over the Netherlands would probably hit 10 or more stations. Note that in this respect "largescale" does not refer to the precipitation type, just to the spatial scale of the event.

In the Netherlands, the most extreme hourly precipitation measurements are almost always part of a large-scale event. For instance, taking only events with maximum hourly precipitation over $30 \mathrm{~mm} \mathrm{~h}^{-1}, 4$ occur in small-scale events and 28 in large-scale events. We define the peak intensity of an event as the maximum of all hourly precipitation measurements (over time and space) connected to the event. We obtain a large difference between large-scale and small-scale events in the distribution of peak intensities; the probability of exceeding a high precipitation threshold is about 1 to 2 orders of magnitude larger for large-scale events (Fig. 3c). This primarily results from the fact that largescale events are associated with significantly more rainfall measurements. Computing the distribution of all rainfall measurements, taken at all times and for all 
TABLE 1. (top) Different intensity precipitation classifications, including the precipitation range in the different humidity classes (L, H, and $\mathrm{XH}$ ). (bottom) Different dewpoint temperature classifications ranging from extra low (XL) to extra high (XH) values, and separate high broad range classification (HR). Bin ID refers to the bin number in the 15-bin classification in right-hand side of Fig. 4.

\begin{tabular}{|c|c|c|c|c|}
\hline \multirow[b]{2}{*}{ Intensity class } & \multirow[b]{2}{*}{ Percentile range } & \multicolumn{3}{|c|}{ Precipitation range at humidity class } \\
\hline & & $\mathrm{L}$ & $\mathrm{H}$ & $\mathrm{XH}$ \\
\hline Dry & - & $0-0.1$ & $0-0.1$ & $0.0-0.0$ \\
\hline Light & $20 \%-40 \%$ & $0.3-0.6$ & $0.3-0.8$ & $0.5-1.6$ \\
\hline Moderate & $50 \%-70 \%$ & $0.8-2.3$ & $1.0-3.9$ & $2.9-8.4$ \\
\hline Heavy & $70 \%-90 \%$ & $2.0-7.7$ & 2.8-11.6 & $8.4-19.9$ \\
\hline Extreme & $>90 \%$ & $6.5-38.8$ & $10.0-72.8$ & $20.3-79.0$ \\
\hline Extreme-20 & $>80 \%$ & $3.6-38.8$ & $5.1-72.8$ & $13.6-79.0$ \\
\hline Humidity classes & Bin ID & Dewpoint range & Wet events & Dry events \\
\hline $\mathrm{XL}$ & $4-6$ & $9.6-11.6$ & 890 & 301 \\
\hline $\mathrm{L}$ & $7-9$ & $11.6-13.4$ & 889 & 242 \\
\hline M & $10-12$ & $13.4-15.3$ & 890 & 228 \\
\hline $\mathrm{H}$ & $13-14$ & $15.4-17.2$ & 594 & 166 \\
\hline $\mathrm{XH}$ & 15 & $17.2-21.8$ & 297 & 75 \\
\hline HR & $11-15$ & $14.5-21.8$ & 1483 & 391 \\
\hline
\end{tabular}

stations, connected to an event and then pooling the data for all large-scale and all small-scale events does not yield a systematic difference in the precipitation statistics of large-scale and small-scale events (Fig. 3d). Again, in a qualitative sense these results are not dependent on the radius used for classifying the precipitation measurement into events: the distribution of peak intensities differs strongly between large-scale and small-scale events, whereas the full distribution is almost identical.

\section{b. Scaling of peak intensities}

For the remainder of this paper we focus on the events occurring in the afternoon and evening, occurring after 1200 UTC and before 2200 UTC (2 p.m. to midnight local time). About $70 \%$ of the events with peak intensities above $20 \mathrm{~mm} \mathrm{~h}^{-1}$ occur in the afternoon and evening. A total of approximately 5000 of these "summertime afternoon" events remain. We also note that the increase in events size with dewpoint temperature is most pronounced in the afternoon data.

We first investigated whether this sample of summertime afternoon events also shows $2 \mathrm{CC}$ behavior. To obtain a sufficiently large sample size in each bin, we used flexible-width bins with a fixed amount of data within a bin. We divided the data with dewpoints above $6^{\circ} \mathrm{C}$ (in total 4500 events) into 15 and 30 bins with an equal number of data, leading to almost 300 and 150 events per bin, respectively.

Within each bin we classified the peak intensity of the events into four different intensity classes based on the percentiles of the distribution: extreme, events above the 90th percentile; heavy, between the 70th and 90th percentiles; moderate, between the 50th and 70th percentiles; and light, between the 20th and 40th percentiles (see Table 1). The median value in the upper three classes, which respectively correspond to the 95th (extreme), 80th (heavy), and the 60th (moderate) percentile of the full distribution, reveals a behavior close to $2 \mathrm{CC}$, with a $14 \%$ increase in peak intensity per degree dewpoint, over the full dewpoint temperature range (Fig. 4). We note that scaling behavior of the light intensity class, corresponding to the 30th percentile, cannot be derived reliably because the intensities are very low, generally lower than $0.5 \mathrm{~mm} \mathrm{~h}^{-1}$ except for the highest dewpoint temperature bin.

The moderate and heavy intensity classes suggest a stronger dependency than 2CC for dewpoints above $16^{\circ} \mathrm{C}$. With the available data we cannot rule out that this is due to chance; however, two results suggest that this could be a systematic behavior. First, for high dewpoint temperatures the behavior of the intensity classes is more regular than in the intermediate temperature regime. This may result from a stronger dominance of convective-type events at high dewpoints, whereas the intermediate range is a mixture of frontal and convective precipitation events. Second, we have already shown an increase in spatial extent of events at high dewpoints, and also the higher probability of a larger peak intensity for the large-scale events.

\section{Analysis of atmospheric conditions}

In the remainder of the paper we analyze average atmospheric conditions for different selections of events based on surface dewpoint and event peak intensity, basically following the scaling diagram (see schematic in Fig. 5). We 1) investigate these atmospheric conditions 

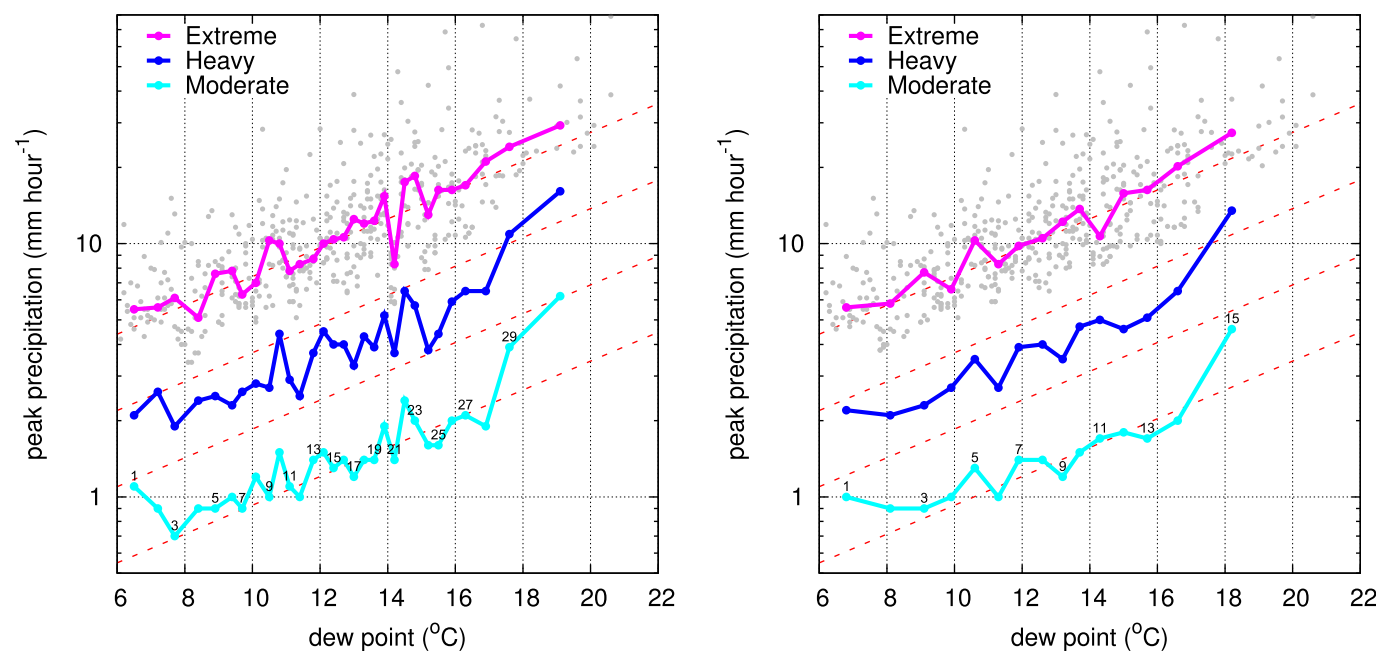

FIG. 4. Scaling of hourly event peak intensities with dewpoint for different intensity classes (see text for details), based on (left) 30 bins and (right) 15 bins, with bin number indicated. The gray dots show the peak intensities in the highest intensity class (extreme). Dashed red lines show dependencies of $14 \%{ }^{\circ} \mathrm{C}^{-1}(\sim 2 \mathrm{CC}$ rate).

as a function of precipitation intensity for a fixed dewpoint temperature (vertical arrow in Fig. 5) and 2) investigate for a given precipitation intensity (relative to its dewpoint) the atmospheric conditions as a function of dewpoint temperature (diagonal arrow following approximately a 2CC dependency in Fig. 5).

We first illustrate the main dependencies, covering the intensity range in section $4 \mathrm{a}$ and humidity range in section $4 \mathrm{~b}$. Relatively large samples of events are chosen here to allow the calculation of statistically robust results. Further, we perform a more comprehensive analysis by combining humidity and intensity dependencies in section $4 \mathrm{c}$.

The selection of events is based on the division of the data into 15 dewpoint temperature bins (right-hand panel of Fig. 4) and the intensity classification (see also Table 1). In the first part of the analysis, to cover a sufficiently large dewpoint range with a limited number of plots we grouped together a number of dewpoint temperature bins into humidity or dewpoint classes. We classify the data into classes with approximately $2^{\circ} \mathrm{C}$ width, ranging from very low (XL; dewpoint around $\left.10^{\circ} \mathrm{C}\right)$ to very high $(\mathrm{XH}$; dewpoint above $17^{\circ} \mathrm{C}$ ) values (see Table 1 ). We also sampled a high humidity range HR by taking bins 11 to 15 together, covering dewpoints of $14^{\circ} \mathrm{C}$ and above. Note that the intensity classification of an event is always relative to its dewpoint temperature bin as shown in Fig. 4b.

\section{a. Differences conditional on intensity for high dewpoints}

We first investigate systematic differences in atmospheric conditions between events with extreme peak intensities and events with lower peak intensities (vertical arrow in Fig. 5). For convenience we omit the reference to peak intensity in the text hereafter, and just call the event "extreme" or "moderate" and refer to the "intensity of the event." Atmospheric profiles are shown as a function of time relative to the occurrence of the peak intensity of the event, ranging from $-12 \mathrm{~h}$ (before) to $+12 \mathrm{~h}$ (after).

We show only the results based on a selection of all events with dewpoint above $14^{\circ} \mathrm{C}$ (the behavior of the events in bins 11 to 15 in Fig. 4b, labeled range $\mathrm{RH}$ in Table 1). Choosing a large range of dewpoint

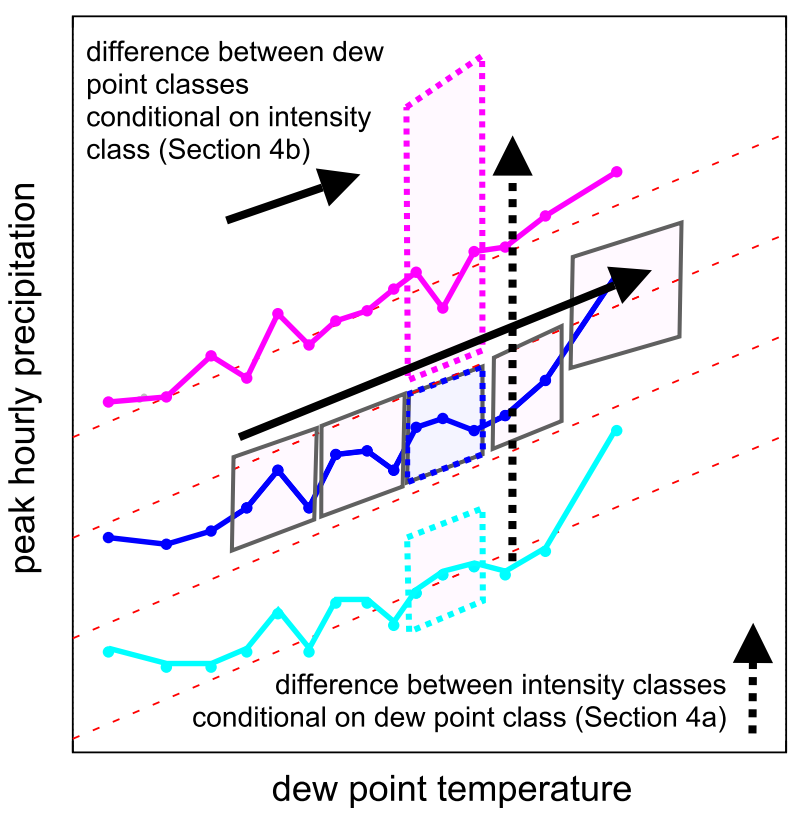

FIG. 5. Idealized diagram of the analysis methodology. 

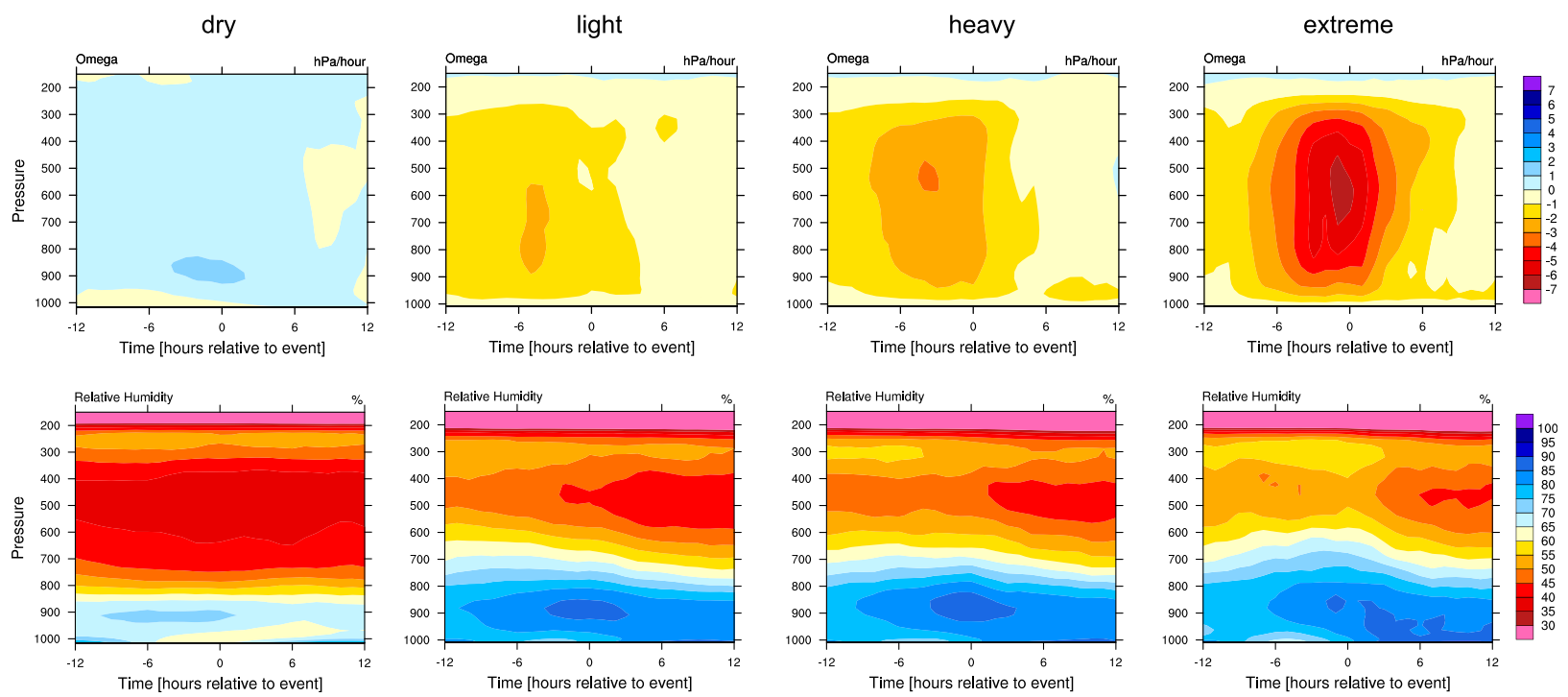

FIG. 6. Large-scale vertical velocity omega (with negative values representing upward motions) and relative humidity as function of height $(\mathrm{hPa})$ and time with respect to the hour of peak intensity of the event.

temperatures ensures a large sample size-there are 152 events classified as extreme in this selection-and taking a high dewpoint temperature also ensures that we capture the most extreme events in absolute terms from the dataset. These results are representative of the typical dependencies found in the separate humidity classifications; a more systematic investigation is performed in section $4 \mathrm{c}$.

Figure 6 shows that the large-scale vertical velocity, omega, reveals a clear signal that distinguishes extreme events from heavy, moderate (not shown here), light, and dry events. Dry events are characterized by, on average, weak subsiding motions (Fig. 6, left panel). Light to heavy events are characterized by weak rising motions, with maximum values occurring a few hours before the event of $-2 \mathrm{hPah}^{-1}$ for the light events and $-3 \mathrm{hPah}{ }^{-1}$ for heavy events. The most extreme events (upper $10 \%$, Fig. 6, right panel) are accompanied by much stronger rising motions, with maximum omega values of $-6 \mathrm{hPah}^{-1}$.

Profiles of relative humidity show a clear difference between dry and wet events, but almost no relation with the intensity of the event (Fig. 6). Dry events are characterized by, on average, $15 \%-25 \%$ lower relative humidity at levels between 600 and $900 \mathrm{hPa}$. Thus, it appears that a dry atmosphere at the top of the boundary layer up to approximately $5 \mathrm{~km}$ provides an environment too hostile for a moist convective updraft to develop into a precipitating cloud.

As a measure of atmospheric instability we show the virtual temperature excess of a moist parcel lifted pseudoadiabatically from the surface using the observed 2-m temperature and humidity (Fig. 7). The ice phase is neglected. The vertical integral of the virtual temperature excess is the convective available potential energy, but the vertical profile also displays information on where the atmosphere is most unstable and how deeply the clouds can develop. There is a moderate increase in instability from light to extreme events. In contrast to the large-scale vertical velocity, which has a rather diffuse maximum at the time of peak intensity or slightly earlier, the temperature excess clearly peaks at $2-4 \mathrm{~h}$ prior to the peak of the rainfall event. At the peak intensity the temperature excess of the updraft is very small. This is because a shower almost always causes a strong cooling near to the surface, leading to a strong reduction of the temperature excess of the parcel. We note here that the updraft calculation uses the observed 2-m temperature, so this effect is realistically represented in our calculation.

Finally, we show the time evolution of the temperature in the atmospheric boundary layer (approximately the lowest $2 \mathrm{~km}$ of the atmosphere) as an anomaly with respect to the time averaged profile (Fig. 7, lowest half). A clear diurnal cycle is shown for all selections, which relates to the fact that we have selected only events occurring in the afternoon and evening. There are also small differences between dry, light, moderate (not shown), and heavy events. Dry events have stronger diurnal temperature cycle near to the surface, which relates to the stronger development of a stable boundary layer at night. The most extreme events, however, are characterized by a stronger warming and a deeper 
dry
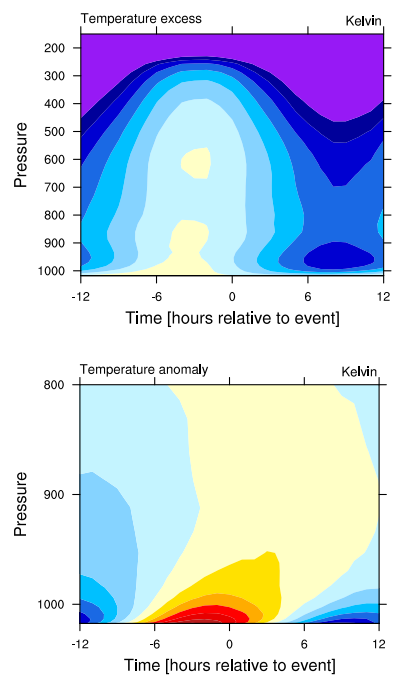

light
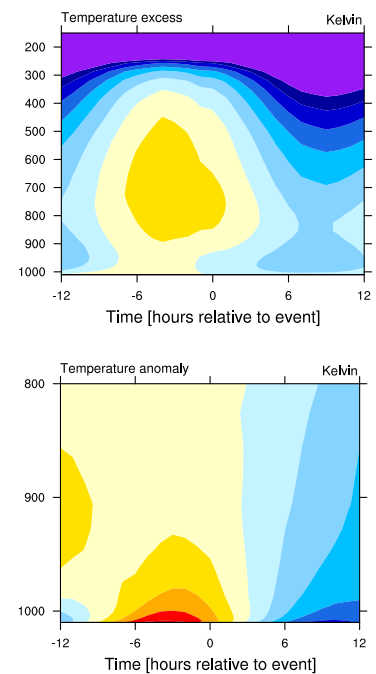

heavy
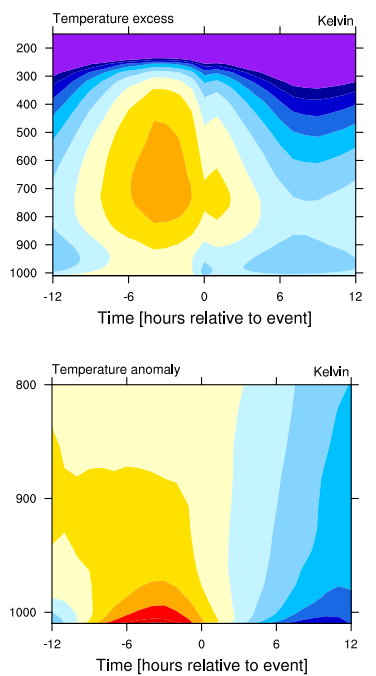

extreme
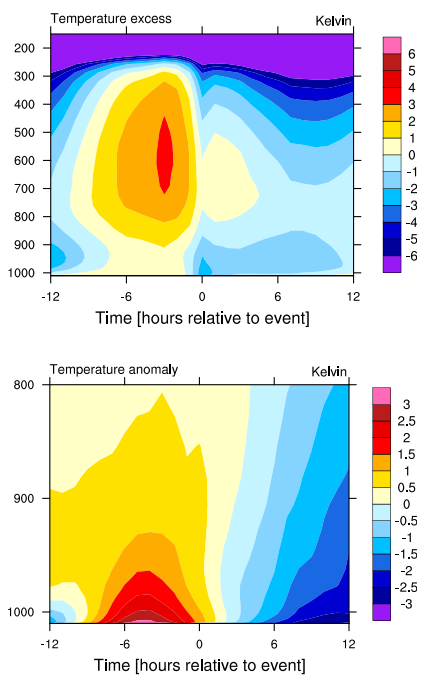

FIG. 7. As in Fig. 6, but now for temperature excess of a moist updraft lifted from the surface, and the temperature anomaly with respect to the time-averaged profile in the lowest part of the atmosphere, showing the diurnal cycle in the atmospheric boundary layer.

boundary layer before the event, and a stronger cooling thereafter (Fig. 7, right lower panel).

\section{b. Differences conditional on dewpoint temperature for extreme events}

We now investigate the atmospheric conditions as a function of dewpoint temperature (diagonal arrow in Fig. 5) for the $20 \%$ most intense events, labeled "extreme-80" in Table 1 . We note that the results of the extreme (above the 90th percentile) and heavy (between the 70th and 90th percentiles) classifications are qualitatively similar, yet with more noise in particular for the highest humidity class $(\mathrm{XH})$, which contains the lowest number of events.

Within these extreme- 80 events the large-scale vertical velocity omega shows almost no change with surface dewpoint temperature up to dewpoint temperature class $M$ (see Table 1 for the dewpoint temperature ranges corresponding to the different classes). For higher dewpoint temperatures than class $\mathrm{M}$ a pronounced increase in omega is found, in particular for atmospheric levels above $500 \mathrm{hPa}$ (Fig. 8, upper panel).

The relative humidity in the low humidity range (classes XL to M) also does not show a clear variation with surface dewpoint. However, for the high dewpoint classes $(\mathrm{H}$ and $\mathrm{XH})$ a gradual decrease in relative humidity is found (Fig. 8, lower panel). Relative humidity in the highest humidity class is about $5 \%$ to $10 \%$ lower than the relative humidity in the lowest dewpoint classes.

The temperature excess of a moist parcel initialized at the surface reveals a very substantial increase with surface dewpoint, in particular for the highest dewpoint class (Fig. 9, upper panel). Also, a pronounced deepening is obtained with increase in surface humidity. For the lowest dewpoint temperature class (XL) the temperature excess becomes negative at $\sim 500 \mathrm{hPa}$, whereas the highest dewpoint class (XH) shows a positive temperature excess up to the tropopause at $\sim 200 \mathrm{hPa}$. This clearly shows the potential for deeper convective clouds with moister surface conditions.

The updraft temperature excess of a moist parcel at a certain height is determined by the temperature difference between that height and the surface and the amount of latent heat release in the lifted parcel. To separate out the role of moisture and temperature, we computed the temperature "excess" of a dry adiabatic parcel in which the latent heat release is neglected. If the temperature of the atmosphere followed a dry adiabatic lapse rate-which actually never happens at such heights, as the atmosphere would have become unstable in terms of moist processes much earlier-then this dry temperature excess would be zero. The time evolution of the dry temperature excess at 3- and 5-km height reveals some systematic differences for the different humidity classes (Figs. 10a,b). These variations with time are mainly determined by the time evolution of the surface temperature, which is used to initialize the parcel. Near-surface cooling occurs due to cold air from downdrafts and evaporation of rain, but also large-scale advection. The temperature at a height above $4 \mathrm{~km}$ only displays small variations with time, typically within $0.5^{\circ} \mathrm{C}$ (not shown), with the exception of a slightly stronger cooling of up to $1.0^{\circ} \mathrm{C}$ for the most extreme events at $6 \mathrm{~h}$ after the event and later. 

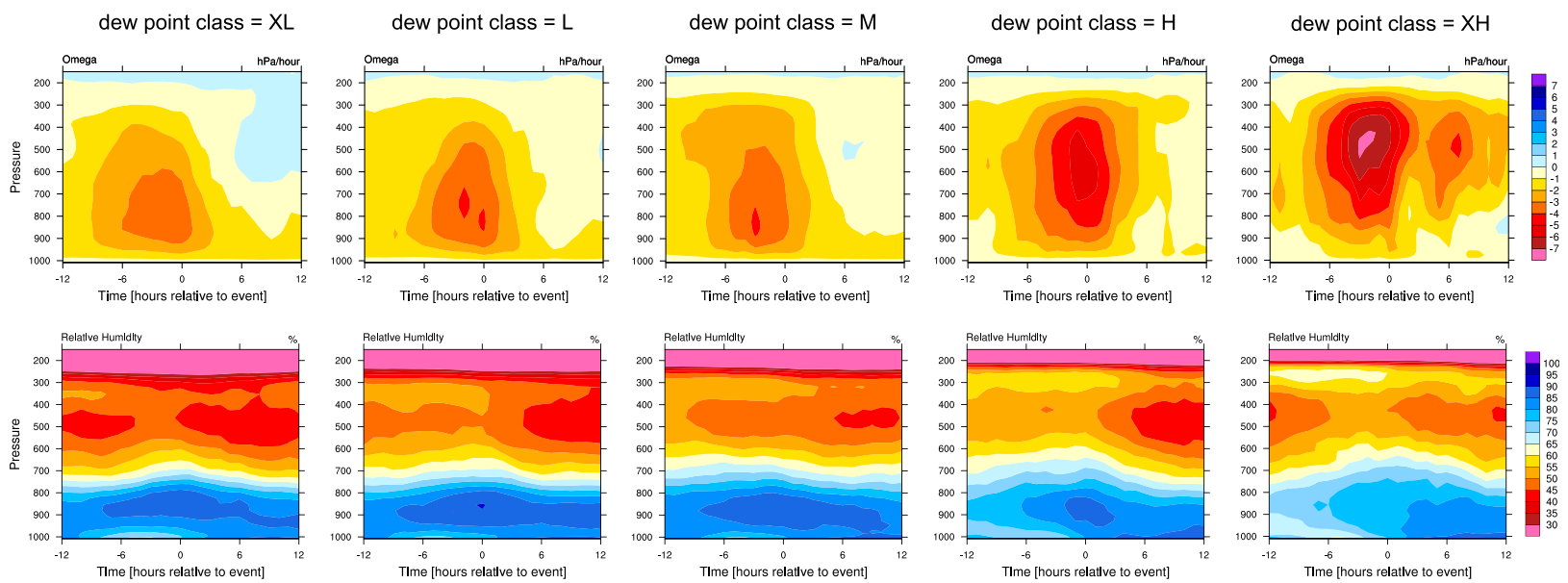

FIG. 8. As in Fig. 6, but now for the $20 \%$ most extreme events (conditioned on dewpoint temperature) with different humidity classes (as defined in Table 1) from left to right.

At $12 \mathrm{~h}$ before the event the dry stability is greater (more stable) for the higher humidity classes. However, the greater warming at the surface and in the boundary layer (Fig. 9, lower panel) compensates for this greater stability. The result is that, in the hours preceeding the shower up to $6 \mathrm{~h}$ before, the differences in dry temperature excess for the different dewpoint temperature classes are very small, and overall the atmosphere is slightly more unstable for the low humidity classes (see, e.g., the XL class at 5-km height). However, the moist temperature excess at 5-km height (Fig. 10c) shows a distinct increase in instability from dry to moist surface conditions.

As $3 \mathrm{~h}$ before the peak intensity is the timing of maximum atmospheric instability, such as measured by CAPE, we believe that the atmospheric profiles at that time are most relevant for determining precipitation intensity. In support of this, we note that the maximum correlation between CAPE and peak intensity is found using CAPE derived for $3 \mathrm{~h}$ before the peak intensity (Loriaux et al. 2016). The increase in the moist instability of the atmosphere with surface dewpoint in the hours before the occurrence of the peak intensity is entirely related to the surface moisture content.

\section{c. Combined results}

Here, we compared the magnitude of changes in atmospheric conditions as a function of precipitation intensity (with fixed dewpoint) versus atmospheric changes related to variations in the dewpoint (with fixed relative intensity) in a more systematic way. We use intensity classifications from "dry" to "extreme" (see
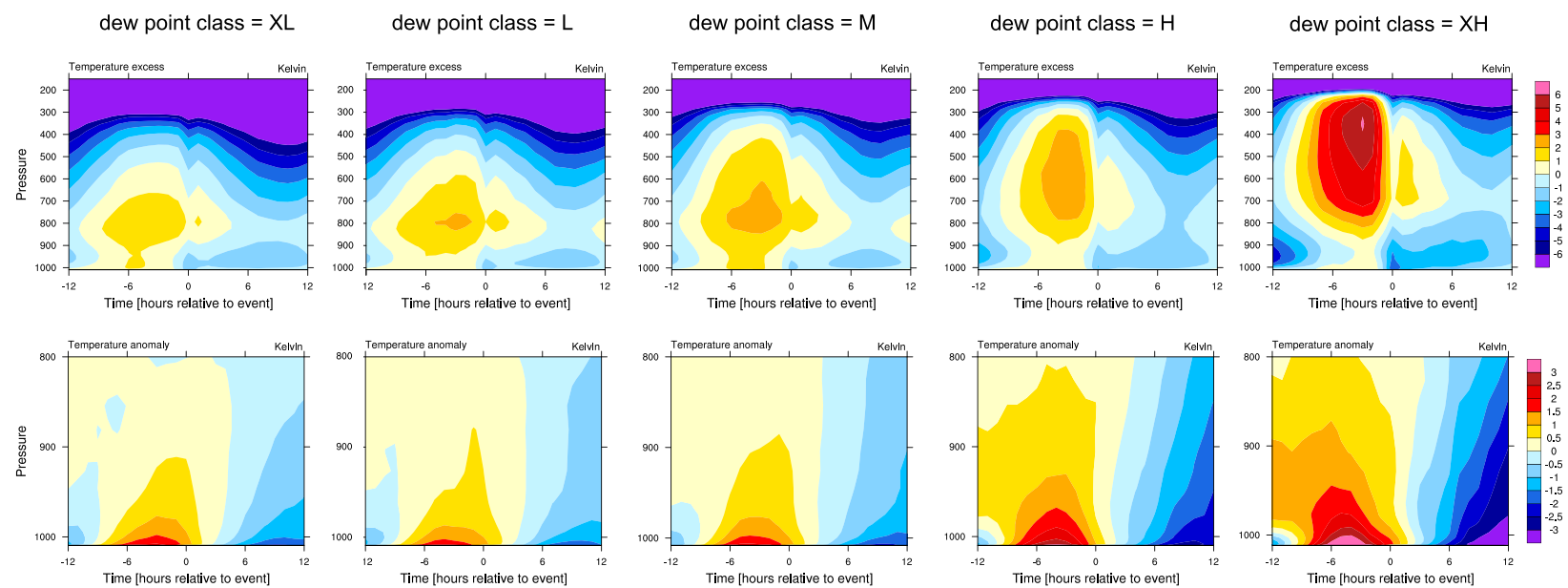

FIG. 9. As in Fig. 7, but now for the $20 \%$ most extreme events (conditioned on dewpoint temperature) with different humidity classes (as defined in Table 1) from left to right. 

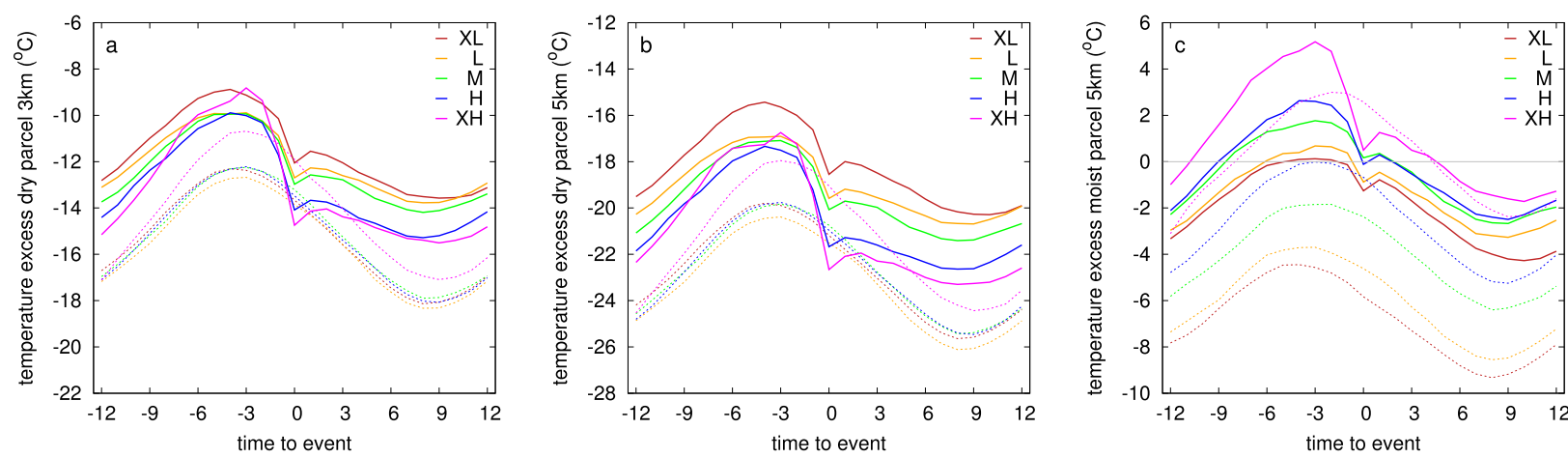

FIG. 10. (a),(b) Temperature difference (excess) between a dry adiabatic parcel lifted from the surface to $3 \mathrm{~km}, 5 \mathrm{~km}$, and the actual temperature at that height (a measure of dry stability with higher values closer to zero indicating more unstable conditions). (c) Temperature difference between a moist adiabat lifted from the surface to $5 \mathrm{~km}$ and the actual temperature at that height (a measure of moist instability). Dashed lines are the averages over dry events, whereas solid lines are the averages over the heaviest $20 \%$ of events.

Table 1) and the humidity bins shown in Fig. 4b (based on 15 bins, with the 3 driest bins not shown in the following plots). To estimate the uncertainty, we use a bootstrap resampling with replacement (assuming independency of the events) and show the 5\%-95\% percentiles from the bootstrap resamples.

To investigate whether the increase in vertical velocity with increasing surface dewpoint is systematic, we computed the average vertical velocity from 300 to $500 \mathrm{hPa}$ and from 600 to $800 \mathrm{hPa}$. Both are averaged over the period from $7 \mathrm{~h}$ before until $2 \mathrm{~h}$ after the event, which is the time period of maximum velocity in Fig. 6 . We find there is a systematic and substantial increase in vertical velocity with near surface dewpoint at high levels, whereas at low levels there is a small nonsignificant increase (Figs. 11a,b). It is noteworthy that the increase in vertical velocity at high levels resembles the increase in moist parcel temperature excess at those levels (Fig. 9), which suggests that the convective activity could be the driver of the increase in large-scale vertical velocity. To quantify this, we employed the quasigeostrophic omega equation and used a typical heating rate of $5^{\circ} \mathrm{Cday}^{-1}$ associated with a selection of extreme events as shown in Fig. 4 of Loriaux et al. (2016). Under simplifying assumptions following Nie and Sobel (2016) this gives omega values of approximately $4 \mathrm{hPah}^{-1}$, supporting that convective activity could change the large-scale circulation (see the supplemental material).

Events in the most extreme intensity classification are accompanied by, on average, substantially higher largescale vertical velocity, in particular at lower levels. As vertical velocity is associated with the horizontal convergence of air masses and therefore moisture convergence, it is of interest to investigate the possible role of large-scale moisture budgets in determining the scaling of peak intensities. To elaborate, we first computed the total precipitation from $12 \mathrm{~h}$ before to $12 \mathrm{~h}$ after the hour of peak intensity, averaged over all stations (Fig. 11c). This shows substantial precipitation amounts of the order of 4-8 $\mathrm{mm} \mathrm{day}^{-1}$, and is a counter image of the average vertical velocity below $500 \mathrm{hPa}$ (Fig. 11a), with relatively small differences for the light to heavy classifications, but considerably larger values for the extreme intensity classification.

To quantify the moisture budget further we computed the moisture convergence according to Loriaux et al. (2017) for the total atmospheric column, and also for levels below $500 \mathrm{hPa}$ and above (Figs. 11d-f). We found an increase in moisture convergence with dewpoint temperature, with the extreme intensity class from approximately 4 to $5 \mathrm{~mm} \mathrm{day}^{-1}$ for the low dewpoint temperature range increasing to $7 \mathrm{~mm} \mathrm{day}^{-1}$ for the highest dewpoint temperature range. This increase follows approximately CC scaling and this is expected from the increase in humidity of the atmosphere (Loriaux et al. 2017). The influence of the changes in the vertical velocity is small, since most of the moisture convergence takes place in the lower troposphere. Increases at high altitudes are more substantial in relative terms due to the increase in vertical velocity, but contribute relatively little to the total moisture convergence. However, for the highest dewpoint temperatures the contribution at high levels becomes substantial with about $25 \%$ of the total moisture convergence. Thus, our results point at a positive feedback related to large-scale moisture convergence for the high dewpoint temperature range.

There is little correlation between the relative humidity at different levels in the atmosphere and the peak precipitation intensity (Figs. 12a-c). The most extreme events occur on average with slightly higher relative humidity at around 5-km height. Near-surface humidity and humidity at the boundary layer top (between 1.5 and $2 \mathrm{~km}$ ) do not reveal any dependency. Yet, there is a very clear distinction between the "dry" events, and wet 

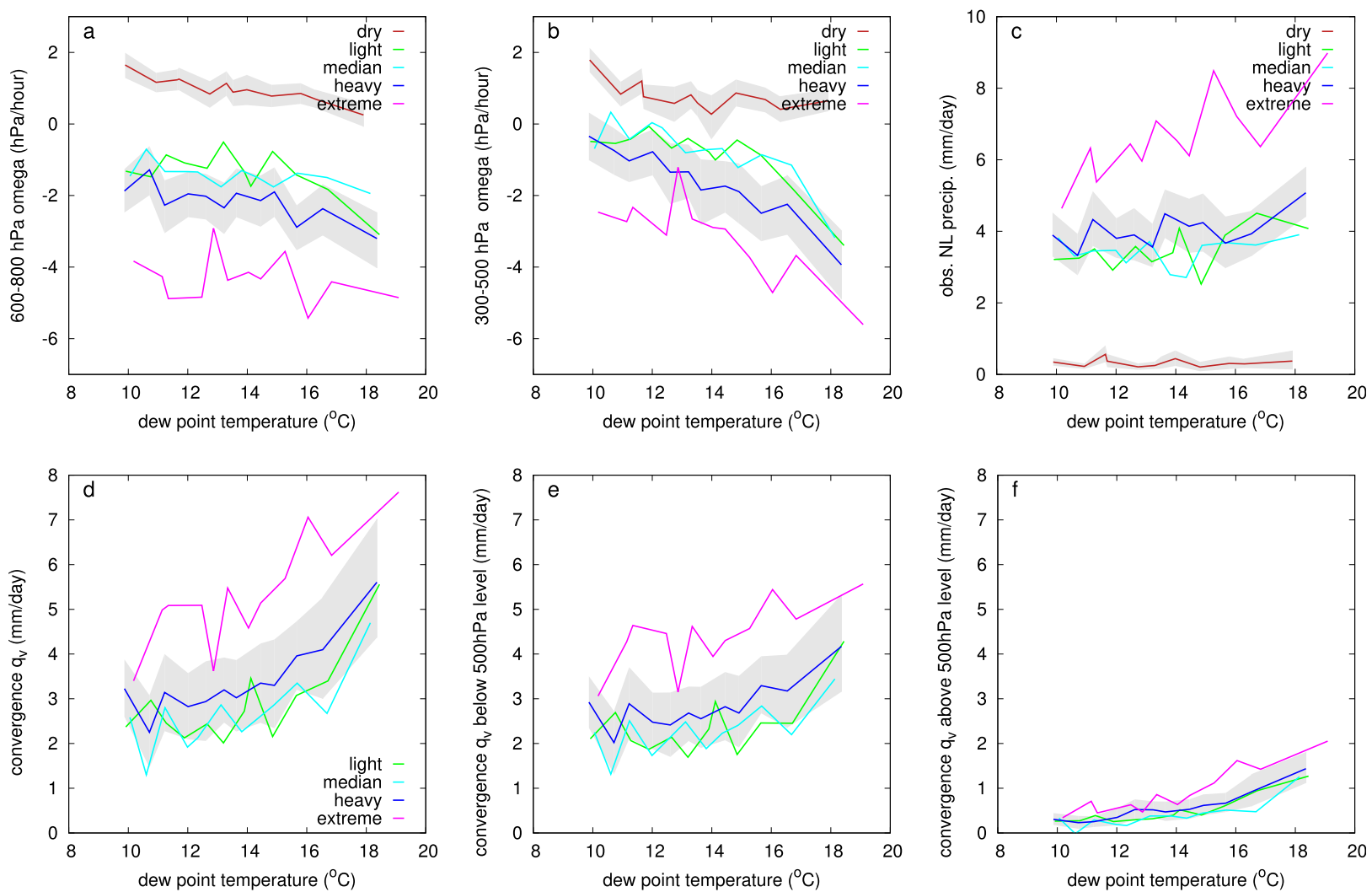

FIG. 11. Different measures related to the moisture budget as a function of dewpoint and intensity class. (a),(b) Average vertical velocity omega in the upper atmosphere $(300-500 \mathrm{hPa})$ and lower atmosphere $(600-800 \mathrm{hPa})$. (c) daily precipitation sum averaged over all stations. (d)-(f) Moisture convergence computed from the vertical velocity and the humidity field, summed over the day $(-12$ to $+12 \mathrm{~h}$ with respect to the event), in the total atmospheric column and in the lower and upper atmosphere, respectively. The vertical velocity is averaged from -7 to $+2 \mathrm{~h}$; the other variables are summed over -12 to $+12 \mathrm{~h}$.

events, in particular for relative humidity at the boundary layer top with wet events occurring for relative humidity values that are approximately $25 \%-30 \%$ higher.

In terms of dry stability, higher intensity events are associated on average with more unstable atmospheric conditions. The dry parcel at $3-\mathrm{km}$ height shows a relatively small temperature difference of $1^{\circ} \mathrm{C}$ between light and intense events, which is almost independent of the dewpoint temperature (Fig. 12d). At 5-km height the discrimination between light and extreme events is slightly stronger for low surface dewpoints. Yet, there is no large systematic change in dry stability with dewpoint temperature, except for a small increase in stability for the most extreme events. In fact, for the highest dewpoint bins the difference in dry stability between the different intensity classifications appears to decrease, which is clearer from the temperature difference between $200 \mathrm{~m}$ and $5 \mathrm{~km}$ as shown in the supplement (see also Figs. 4 and 5).

However, taking latent heat release into account by using a moist parcel, we find a strong increase in instability of the atmosphere with surface dewpoint (Fig. 12f). The differences between the different intensity classes are still governed by the dry temperature lapse rate (cf. Figs. 12e and 12f). However, the overall increase in instability (and related to that also CAPE values; see the supplemental material) with surface dewpoint is very clearly caused by moisture effects.

\section{Conclusions}

In this paper we have presented a comprehensive analysis of atmospheric conditions and hourly rainfall intensity using a relatively dense station network of around 30 stations in the Netherlands (1995 to 2014) combined with a high-resolution reanalysis (Loriaux et al. 2016) based on ERA-Interim (Dee et al. 2011). Precipitation events are defined as wet $(>0.1 \mathrm{~mm})$ hours connected in time and in space within a radius of $70 \mathrm{~km}$.

The peak hourly precipitation intensity-defined as the maximum measured hourly precipitation for all stations and all hours connected to an individual rainfall event — clearly shows a super-CC scaling, close to or even 

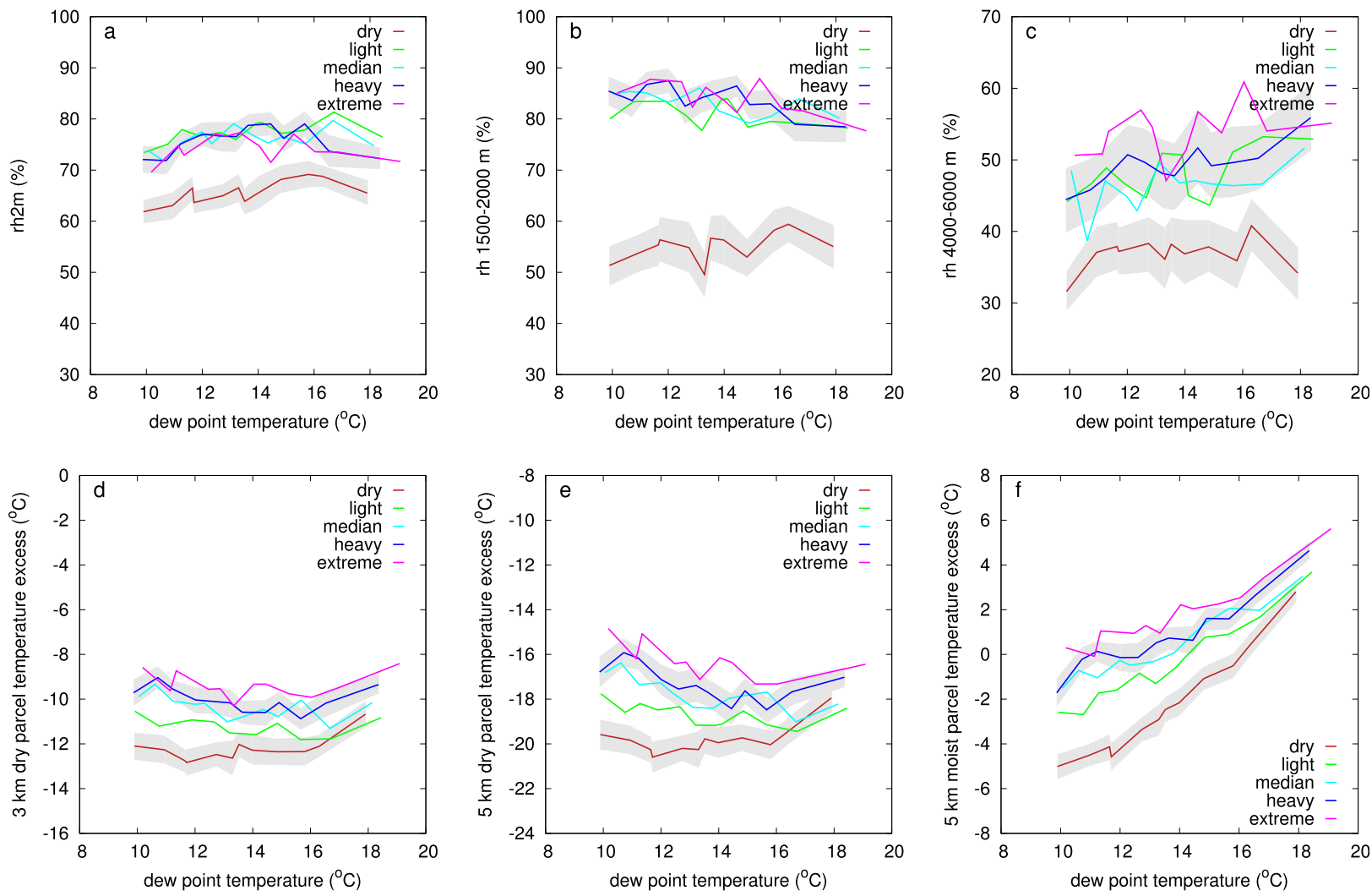

FIG. 12. Different measures related to the atmospheric state as a function of dewpoint and intensity class: (a)-(c) relative humidity at $2 \mathrm{~m}, 1500-2000 \mathrm{~m}$, and 4000-6000 m, respectively; (d),(e) temperature excess of a dry parcel lifted to 3 and $5 \mathrm{~km}$, respectively, and (f) a moist parcel lifted to $5 \mathrm{~km}$. All measures are at $3 \mathrm{~h}$ before the (timing of the peak intensity of the) event.

exceeding the 2CC scaling. The spatial extent of rainfall events appears to increase slightly when surface dewpoints exceed $10^{\circ} \mathrm{C}$. This increase in event size appears to accelerate for dewpoints above $18^{\circ} \mathrm{C}$, hinting at an increasing occurrence of large clustered cloud systems for those high humidity values, in contrast to a decrease in spatial extent as found by Wasko et al. (2016).

Here, we briefly mention the work on tropical convective precipitation showing a rapid increase of convective cluster size, rainfall intensity, and rainfall probability near a critical value of the column water vapor path (WVP), resembling the power-law behavior found near criticality in phase transitions (Peters et al. 2009; Neelin et al. 2009). This critical value of WVP increases slower with temperature than the $\mathrm{CC}$ relation, implying that for a temperature increase (and unchanged relative humidity) the atmosphere moves closer to the critical value and therefore could explain super-CC behavior and/or the rapid increase in events size for high humidity.

The most extreme peak intensities are primarily associated with large-scale events with precipitation at more than $30 \%$ of the stations. This finding is directly related to the greater number of rainfall measurements associated with large-scale events, even despite the fact that the number of large-scale events is only a small fraction of the total number of events.

We further analyzed atmospheric conditions within the framework of the precipitation intensity scaling diagram (see Fig. 5) to investigate the conditions that discriminate extreme events from moderate or weak events (given a certain dewpoint temperature) and determine which aspects change as a function of dewpoint temperature.

Large-scale vertical velocities are typically stronger for extreme events by almost a factor of 2 , on average, compared to events with more moderate precipitation intensities. For a considerable part this large-scale omega is likely forced from the synoptic-scale circulation, but our results also point to a positive feedback due to convection. Changes with dewpoint temperature are small at the lower tropospheric levels, yet there is a clear increase in upper tropospheric vertical velocities with dewpoint temperature. This increase is likely related to the latent heat release due to convection itself, which can be quantified using the quasigeostrophic omega equation (see the supplemental material). Increasing largescale vertical velocities, and the associated large-scale 
moisture convergence, with dewpoint temperature may explain the observed increase in event size with dewpoint temperature.

The atmospheric instability as measured by the temperature excess of a moist parcel lifted from the surface shows a relatively weak increase with peak precipitation intensity, but a strong increase with dewpoint temperature. The latter is entirely due to the surface moisture increase, with more latent heat release producing warmer parcels in the middle and upper part of the troposphere. There are no substantial differences in temperature lapse rate. Also, the lifted parcels reach higher altitudes for moister surface conditions. This result casts doubts upon methods used to discriminate between convective and large-scale precipitation based on cloud-top heights or lightning data. At lower dewpoint temperature convective clouds cannot develop as easily into very deep convective clouds and are less likely to cause lightning given these lower cloud-top heights, lower moist temperature excesses, and associated lower updraft velocities (Boccippio 2002). Thus, there is likely a systematic increase in lightning occurrence and cloud-top height with surface dewpoint temperature that is unrelated to the precipitation type, but is the direct consequence of the invigoration of convection itself.

Examining the cause of the 2CC scaling, we could not find any clear evidence of statistical effects. Precipitation extremes on days with high surface dewpoints occur under similar atmospheric conditions as on days with lower dewpoints, except for those atmospheric parameters that relate directly to the higher surface humidity, such as the CAPE values. There are no substantial differences in relative humidity, dry lapse rate, and (to a lesser degree) largescale vertical velocities. The results clearly show the potential role of local cloud dynamics (through increased buoyancy of the updrafts) and the larger-scale dynamics (through large-scale vertical motions and associated moisture convergence) in explaining 2CC behavior. However, based on our results the influence of other processes, such as dependencies of microphysics on temperature (Singh and O'Gorman 2014), cannot be ruled out.

The results also show the prominent role of large-scale circulation as measured here by the large-scale vertical velocity. Intense events are, on average, associated with high omega values, which cause a substantial convergence of moist air. Additionally, most extremes of hourly precipitation occur in events with a large spatial scale. We hypothesize therefore that $2 \mathrm{CC}$ behavior may only be seen under conditions where the large-scale atmospheric circulation provides sufficient moisture. So, alongside the strong influence of increasing humidity in a warmer climate, changes in large-scale atmospheric flow conditions could also have a strong impact on the frequency of occurrence of extreme hourly precipitation.
Finally, changes in atmospheric stability could play an important role in this context. Climate models predict a warming close to the moist adiabat in the tropics. However, only few studies on stability changes at midlatitudes exist, and results are more diverse, varying between warming close to the moist adiabat (Frierson 2006) and a rather uniform vertical warming (Attema et al. 2014). In this respect, we note that our results also reveal a small increase in dry stability with surface dewpoint temperature in concert with a reduction of the dependency of extreme precipitation on atmospheric stability for high dewpoint temperatures. To summarize, we think that $2 \mathrm{CC}$ behavior as seen in the observations could be indicative of the climate change response of extreme precipitation as supported by trend analyses over the past century for the Netherlands and Hong Kong (Lenderink et al. 2011), but the influence of atmospheric stability changes and the interaction with the large-scale circulation clearly need further investigation.

Acknowledgments. GL, RB, and HJF acknowledge financial support from the project INTENSE, which is supported by the European Research Council (Grant ERC-2013-CoG, Project 617329). HJF is funded by the Wolfson Foundation and is the Royal Society Wolfson Research Merit Award (WM140025) holder.

\section{REFERENCES}

Allen, M. R., and W. J. Ingram, 2002: Constraints on future changes in climate and the hydrologic cycle. Nature, 419, 224-232, doi:10.1038/nature01092.

Attema, J. J., J. M. Loriaux, and G. Lenderink, 2014: Extreme precipitation response to climate perturbations in an atmospheric mesoscale model. Environ. Res. Lett., 9, 014003, doi:10.1088/1748-9326/9/1/014003.

Ban, N., J. Schmidli, and C. Schär, 2015: Heavy precipitation in a changing climate: Does short-term summer precipitation increase faster? Geophys. Res. Lett., 42, 1165-1172, doi:10.1002/ 2014GL062588.

Berg, P., and J. O. Haerter, 2013: Unexpected increase in precipitation intensity with temperature-A result of mixing of precipitation types? Atmos. Res., 119, 56-61, doi:10.1016/ j.atmosres.2011.05.012.

_ C. Moseley, and J. O. Haerter, 2013: Strong increase in convective precipitation in response to higher temperatures. Nat. Geosci., 6, 181-185, doi:10.1038/ngeo1731.

Boccippio, D. J., 2002: Lightning scaling relations revisited. J. Atmos. Sci., 59, 1086-1104, doi:10.1175/1520-0469(2002)059<1086: LSRR $>2.0 . C O ; 2$.

Davies, L., C. Jakob, P. May, V. V. Kumar, and S. Xie, 2013: Relationships between the large-scale atmosphere and the smallscale convective state for Darwin, Australia. J. Geophys. Res. Atmos., 118, 11 534-11 545, doi:10.1002/jgrd.50645.

Dee, D. P., and Coauthors, 2011: The ERA-Interim reanalysis: Configuration and performance of the data assimilation system. Quart. J. Roy. Meteor. Soc., 137, 553-597, doi:10.1002/qj.828.

Doswell, C. A., H. E. Brooks, and R. A. Maddox, 1996: Flash flood forecasting: An ingredients-based methodology. Wea. 
Forecasting, 11, 560-581, doi:10.1175/1520-0434(1996)011<0560: FFFAIB $>2.0 . \mathrm{CO} ; 2$

Drobinski, P., and Coauthors, 2017: Scaling precipitation extremes with temperature in the Mediterranean: Past climate assessment and projection in anthropogenic scenarios. Climate Dyn., doi:10.1007/s00382-016-3083-x, in press.

Fischer, E. M., and R. Knutti, 2016: Observed heavy precipitation increase confirms theory and early models. Nat. Climate Change, 6, 986-991, doi:10.1038/nclimate3110.

Frierson, D. M. W., 2006: Robust increases in midlatitude static stability in simulations of global warming. Geophys. Res. Lett., 33, L24816, doi:10.1029/2006GL027504.

Haerter, J. O., and P. Berg, 2009: Unexpected rise in extreme precipitation caused by a shift in rain type? Nat. Geosci., 2 , 372-373, doi:10.1038/ngeo523.

Hand, W. H., N. I. Fox, and C. G. Collier, 2004: A study of twentieth-century extreme rainfall events in the United Kingdom with implications for forecasting. Meteor. Appl., 11, 15-31, doi:10.1017/S1350482703001117.

Hardwick Jones, R., S. Westra, and A. Sharma, 2010: Observed relationships between extreme sub-daily precipitation, surface temperature, and relative humidity. Geophys. Res. Lett., 37, L22805, doi:10.1029/2010GL045081.

Houze, R. A., 2004: Mesoscale convective systems. Rev. Geophys., 42, 1-43, doi:10.1029/2004RG000150.

Ivancic, T. J., and S. B. Shaw, 2016: A U.S.-based analysis of the ability of the Clausius-Clapeyron relationship to explain changes in extreme rainfall with changing temperature. J. Geophys. Res. Atmos., 121, 3066-3078, doi:10.1002/2015JD024288.

Kendon, E. J., N. M. Roberts, H. J. Fowler, M. J. Roberts, S. C. Chan, and C. A. Senior, 2014: Heavier summer downpours with climate change revealed by weather forecast resolution model. Nat. Climate Change, 4, 570-576, doi:10.1038/nclimate2258.

Lenderink, G., and E. van Meijgaard, 2008: Increase in hourly extreme precipitation beyond expectation from temperature changes. Nat. Geosci., 1, 511-514, doi:10.1038/ngeo262.

$\longrightarrow$, and _ 2010: Linking increases in hourly precipitation extremes to atmospheric temperature and moisture changes. Environ. Res. Lett., 5, 025208, doi:10.1088/1748-9326/5/2/025208.

_ climate scenarios of local precipitation extremes for the Netherlands. Environ. Res. Lett., 10, 085001, doi:10.1088/ 1748-9326/10/8/085001.

— - H. Y. Mok, T. C. Lee, and G. J. van Oldenborgh, 2011: Scaling and trends of hourly precipitation extremes in two different climate zones-Hong Kong and the Netherlands. Hydrol. Earth Syst. Sci., 15, 3033-3041, doi:10.5194/hess-15-3033-2011.

Lepore, C., J. T. Allen, and M. K. Tippett, 2016: Relationships between hourly rainfall intensity and atmospheric variables over the contiguous United States. J. Climate, 29, 3181-3197, doi:10.1175/JCLI-D-15-0331.1.

Loriaux, J. M., G. Lenderink, S. R. De Roode, and P. Siebesma, 2013: Understanding convective extreme precipitation scaling using observations and an entraining plume model. J. Atmos. Sci., 70, 3641-3655, doi:10.1175/JAS-D-12-0317.1.

,-- , and A. P. Siebesma, 2016: Peak precipitation intensity in relation to atmospheric conditions and large-scale forcing at midlatitudes. J. Geophys. Res. Atmos., 121, 5471-5487, doi:10.1002/2015JD024274.

$\ldots, \ldots$, and _ 2017: Large-scale controls on extreme precipitation. J. Climate, 30, 955-968, doi:10.1175/JCLI-D-16-0381.1.

Meredith, E. P., D. Maraun, V. A. Semenov, and W. Park, 2015: Evidence for added value of convection-permitting models for studying changes in extreme precipitation. J. Geophys. Res. Atmos., 120, 12 500-12 513, doi:10.1002/2015JD024238.

Mishra, V., J. M. Wallace, and D. P. Lettenmaier, 2012: Relationship between hourly extreme precipitation and local air temperature in the United States. Geophys. Res. Lett., 39, L16403, doi:10.1029/2012GL052790.

Molnar, P., S. Fatichi, L. Gaál, J. Szolgay, and P. Burlando, 2015: Storm type effects on super Clausius-Clapeyron scaling of intense rainstorm properties with air temperature. Hydrol. Earth Syst. Sci., 19, 1753-1766, doi:10.5194/hess-19-1753-2015.

Muller, C. J., P. A. O'Gorman, and L. E. Back, 2011: Intensification of precipitation extremes with warming in a cloud-resolving model. J. Climate, 24, 2784-2800, doi:10.1175/2011JCLI3876.1.

Neelin, J. D., O. Peters, and K. Hales, 2009: The transition to strong convection. J. Atmos. Sci., 66, 2367-2384, doi:10.1175/ 2009JAS2962.1.

Nie, J., and A. H. Sobel, 2016: Modeling the interaction between quasigeostrophic vertical motion and convection in a single column. J. Atmos. Sci., 73, 1101-1117, doi:10.1175/JAS-D-15-0205.1.

O'Gorman, P. A., 2015: Precipitation extremes under climate change. Curr. Climate Change Rep., 1, 49-59, doi:10.1007/ s40641-015-0009-3.

Pall, P., M. R. Allen, and D. A. Stone, 2007: Testing the ClausiusClapeyron constraint on changes in extreme precipitation under $\mathrm{CO}_{2}$ warming. Climate Dyn., 28, 351-363, doi:10.1007/ s00382-006-0180-2.

Panthou, G., A. Mailhot, E. Laurence, and G. Talbot, 2014: Relationship between surface temperature and extreme rainfalls: A multi-time-scale and event-based analysis. J. Hydrometeor., 15, 1999-2011, doi:10.1175/JHM-D-14-0020.1.

Peters, O., J. D. Neelin, and S. W. Nesbitt, 2009: Mesoscale convective systems and critical clusters. J. Atmos. Sci., 66, 2913 2924, doi:10.1175/2008JAS2761.1.

Prein, A. F., and Coauthors, 2015: A review on regional convection-permitting climate modeling: Demonstrations, prospects, and challenges. Rev. Geophys., 53, 323-361, doi:10.1002/2014RG000475.

Romps, D. M., 2011: Response of tropical precipitation to global warming. J. Atmos. Sci., 68, 123-138, doi:10.1175/2010JAS3542.1.

Singh, M. S., and P. A. O'Gorman, 2014: Influence of microphysics on the scaling of precipitation extremes with temperature. Geophys. Res. Lett., 41, 6037-6044, doi:10.1002/2014GL061222.

Singleton, A., and R. Toumi, 2013: Super-Clausius-Clapeyron scaling of rainfall in a model squall line. Quart. J. Roy. Meteor. Soc., 139, 334-339, doi:10.1002/qj.1919.

Trenberth, K. E., A. Dai, R. M. Rasmussen, and D. B. Parsons, 2003: The changing character of precipitation. Bull. Amer. Meteor. Soc., 84, 1205-1217, doi:10.1175/BAMS-84-9-1205.

van Meijgaard, E., L. H. van Ulft, G. Lenderink, S. R. de Roode, L. Wipfler, R. Boers, and R. M. A. Timmermans, 2012: Refinement and application of a regional atmospheric model for climate scenario calculations of western Europe. KNMI Rep. KvR-054/12, 44 pp.

van Oldenborgh, G. J., and Coauthors, 2016: Rapid attribution of the May/June 2016 flood-inducing precipitation in France and Germany to climate change. Hydrol. Earth Syst. Sci. Discuss., 3, 1-23, doi:10.5194/hess-2016-308.

Wasko, C., A. Sharma, and S. Westra, 2016: Reduced spatial extent of extreme storms at higher temperatures. Geophys. Res. Lett., 43, 4026-4032, doi:10.1002/2016GL068509.

Westra, S., and Coauthors, 2014: Future changes to the intensity and frequency of short-duration extreme rainfall. Rev. Geophys., 52, 522-555, doi:10.1002/2014RG000464. 